\title{
OBSERVATIONS OF SHORT PERIOD MESOSPHERIC WAVE PATTERNS: IN SITU OR TROPOSPHERIC WAVE GENERATION?
}

\author{
M.J. Taylor, and R. Edwards \\ Physics Department, University of Southampton, \\ Southampton, $\mathrm{SO} 95 \mathrm{NH}$, U.K.
}

\begin{abstract}
Near infrared images showing wave structure in the hydroxyl $(\mathrm{OH})$ nightglow emission have been obtained from Maui, Hawaii during the ALOHA-90 campaign. Analysis of two nights during this campaign (25 and 31 March) indicate extensive, highly coherent, linear wave patterns of very short apparent period $(\sim 5$ and 10 min respectively). Both displays exhibited several features characteristic of the in situ breakdown of a large scale, long period, upper atmospheric wave disturbance. Data in support of this mechanism was found by other ALOHA instruments which detected concurrent long period (1-2 hour) mesospheric wave disturbances on both occasions. However, a tropospheric source for these waves cannot be ruled out. At least on 25 March a weather front occurred at $\sim 1400 \mathrm{~km}$ range with a favourable orientation and location. Although its range was relatively large, background winds may have substantially increased the path length of the waves through the intervening atmosphere.
\end{abstract}

\section{Introduction}

The presence of coherent wave structure in the midlatitude mesospheric nightglow emissions is well established [Moreels and Herse, 1977; Armstrong, 1986; Taylor et al., 1987]. Detailed observations have shown that these patterns often exhibit properties associated with short period (10-20 min) gravity waves. During the ALOHA-90 campaign similar morphology wave forms were detected at low latitudes over an ocean site [Taylor and Hill, 1991].

Many sources for these waves have been suggested. They include tropospheric disturbances such as jet streams, storms, weather fronts and the interaction of strong winds with large mountains (generating lee-type gravity waves). Several upper atmospheric sources have also been postulated; they include the auroral electrojet, strong particle precipitation and the in situ breakdown of largescale, long period atmospheric waves such as tides. It is often difficult to identify individual wave sources from the wealth of potential disturbances. For tropospheric sources this problem is further complicated by the effects of background winds in the intervening atmosphere, which can significantly modify the wave propagation. Images of structure in the nightglow emissions give unique 2dimensional information on the horizontal wavelength and apparent phase velocity of the gravity wave perturbation. These data together with the location, shape, orientation

Copyright 1991 by the American Geophysical Union.

Paper number 91GL01516

0094-8534/91/91GL-01516\$3.00 and time of occurrence of the display have proved valuable for finding possible wave sources [Taylor and Hapgood, 1988]. By imaging structure in the nightglow emissions from the Hawaiian islands the sources of short period gravity waves over a low latitude oceanic site can be investigated.

\section{Observations and Results}

Observations were made from the Department of Energy (DOE) building, Haleakala Crater, Maui $\left(20.8^{\circ} \mathrm{N}\right.$, $\left.156.2^{\circ} \mathrm{W}, 2970 \mathrm{~m}\right)$. The high altitude and favourable weather during the campaign (18 March-4 April) provided excellent conditions for imaging structure in the nightglow emissions. The measurements reported here were made with a medium field $\left(55^{\circ}\right) \mathrm{CCD}$ camera filtered to observe the near infra-red (NIR) $\mathrm{OH}$ nightglow emission (wavelength range $780 \sim 1000 \mathrm{~nm}$ ). Further details of the instrumentation are given in the ALOHA-90 overview paper [Gardner, 1991]. Wave patterns were imaged on several occasions during the campaign [Taylor and Hill, 1991]. In this report the properties of two faint wave displays imaged on 25 March and 31 March are examined and compared with simultaneous airborne and ground based measurements.

\section{March Display}

Observations were made from 06:00 UT until dawn twilight at 15:40 UT. A well formed set of steeply inclined wave-like structures was detected at low elevation to the northeast. Figure 1 shows a CCD image of the NIR display at 07:10 UT. Several faint forms emanating from the northeastern horizon are evident. The structures are clearest on the right of the image but the data shows that similarly orientated wave crests exist across the whole field. The uniformity of the wave pattern is quite remarkable. The display was clearest around 06:30-08:00 UT, but was still evident at 11:00 UT nearly 5 hours later.

A similarly shaped but fainter wave pattern was also detected to the southwest of the site. Figure 2 shows a composite ground map of the nightglow display imaged to the northeast at 07:10 UT (Figure 1) and an hour later to the southwest. The flight path of the aircraft during this night is also marked on the figure. Each image was calibrated using known stars as reference points [Hapgood and Taylor, 1982] and mapped onto the ground assuming an $\mathrm{OH}$ emission altitude of $87 \mathrm{~km}$. The geographical location and orientation of the two wave sets indicates an extensive, spatially and temporally coherent display, containing many wave crests $>800 \mathrm{~km}$ in length. To the 




Fig.1 CCD image showing NIR wave structure imaged to the NE on 25 March at 07:10 UT. The camera was aimed at an elevation of $20^{\circ}$ and had a field of view of $55^{\circ}$ by $30^{\circ}$.

south, in the direction of the airborne measurements, there was no obvious wave structure, but this direction was affected by light from the Milky Way. The average separation of the wave crests, determined from several images, gave a horizontal wavelength $\left(\lambda_{x}\right)$ of $15.2 \pm 0.6$ $\mathrm{km}$. The displacement of the wave crests (measured over an interval of $90 \mathrm{~min}$ ) yielded a mean velocity $\left(v_{x}\right)$ of $51 \pm$ $5 \mathrm{~ms}^{-1}$ towards the southeast, indicating an unusually short apparent wave period $(\tau)$ of $5.0 \pm 0.5$ minutes.

\section{March Display}

During this night wave structure was detected at most azımuths but was clearest to the west and north. To the

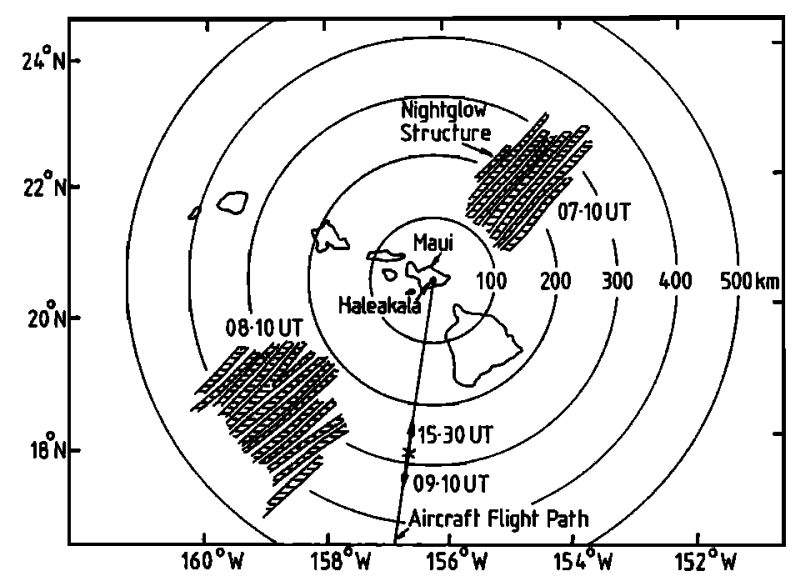

Fig.2 Composite map showing the scale size and geographic location of the $\mathrm{OH}$ wave forms imaged to the $\mathrm{NE}$ and SW of Maui on 25 March, assuming an emission altitude of $87 \mathrm{~km}$ (only the brightest wave forms have been plotted). The $x$ marks the aircraft location at 09:10 UT on the outward leg and 15:30 UT on the return leg. west the wave pattern consisted of several steeply inclined crests of similar morphology to those observed on 25 March (Figure 1). To the north the wave crests appeared near horizontal. Figure 3 shows a composite ground map of the structures at 09:36 UT (to the west) and 18 minutes later to the north. The coherence of the structures is not as marked as those imaged on 25 March (Figure 2). Nevertheless, the map clearly shows two sections of an extensive wave display viewed at orthogonal azimuths. A series of images obtained at elevation angles ranging from $17^{\circ}$ to $90^{\circ}$ confirmed the existence of coherent wave crests extending from the northern and western horizon through the local zenith. The pattern was present all night indicating a duration of over 6 hours. Measurements of the horizontal parameters of the wave pattern during the

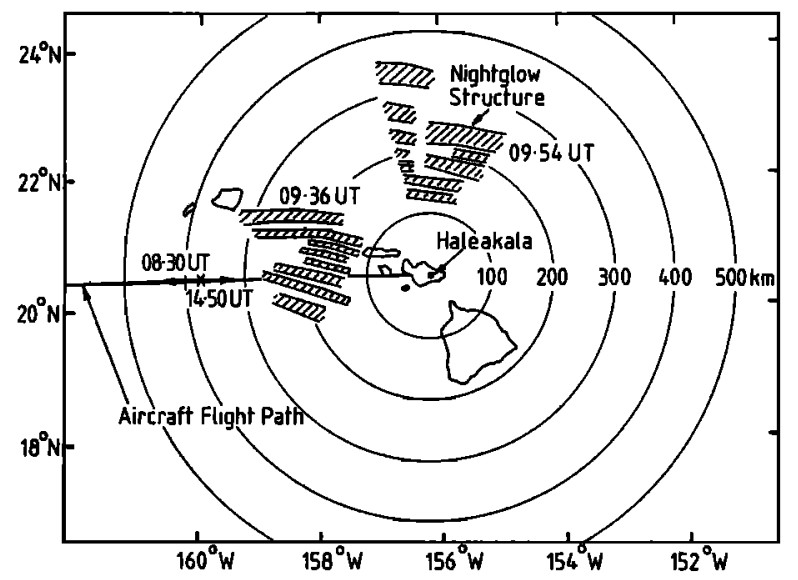

Fig.3 Composite map showing the $\mathrm{OH}$ wave display of 31 March. For comparison the data are plotted on the same scale as Figure 2. The aircraft flew due west almost parallel to the wave structures. 
interval 06:30-08:00 UT gave $\lambda_{\mathrm{x}}=19.8 \pm 0.8 \mathrm{~km}, \mathrm{v}_{\mathrm{x}}=32$ $\pm 4 \mathrm{~ms}^{-1}$ towards the north signifying an apparent wave period $\tau=10.3 \pm 1.4 \mathrm{~min}$.

\section{Discussion}

Both wave patterns were extensive $\left(>250,000 \mathrm{~km}^{2}\right)$, remarkably coherent, and lasted for several hours. Their horizontal wavelengths and linear morphology were also comparable, indicating similar sources for the disturbances. However, the apparent (i.e. observed) wave periods were significantly different at 5.0 and $10.3 \mathrm{~min}$ on 25 and 31 March respectively. In the presence of a background wind the intrinsic period of the gravity wave is Doppler shifted with respect to its apparent period:

$$
\tau_{\mathrm{i}}=\tau\left[\mathrm{v}_{\mathrm{x}} /\left(\mathrm{v}_{\mathrm{x}}-\overline{\mathrm{u}}\right)\right]
$$

where $\overline{\mathrm{u}}$ is the horizontal background wind component in the direction of motion of the wave, $r$ is the apparent period as measured by an observer on the ground and $\tau_{i}$ is the intrinsic (or true) period of the wave measured in a frame of reference moving with the background wind. The intrinsic period of the wave motion may therefore be significantly different from the apparent period of the wave pattern.

The motion of the gravity wave through the atmosphere depends on its intrinsic period [Hines, 1960] which is usually indeterminate. However, as the apparent horizontal velocity of the wave will be independent of the background wind regardless of height [Hines, 1968], measurements of $\lambda_{\mathrm{x}}$ and $\mathrm{v}_{\mathrm{x}}$ of the nightglow wave patterns (and hence $\tau$ ) are very useful for studies of the wave sources. On the other hand, if the waves are generated by a disturbance that is moving with respect to the observer, the apparent period of the wave pattern will vary with $\bar{u}$ at the height of the source.

\section{Tropospheric Source}

The extensive nature and linear form of both $\mathrm{OH}$ displays would suggest either a point-like source such as a thunderstorm [Taylor and Hapgood, 1988] but at a range of at least $1000 \mathrm{~km}$ from the observing site, or an extended "line type" source such as a weather front or a jet stream close to the observing site [Hines, 1968]. Without a measurement of the background wind in the intervening atmosphere it is difficult to estimate the range over which the wave energy can propagate. However, gravity waves generated nearby by strong winds blowing over local island peaks (such as Haleakala Crater) can be effectively ruled out on both occasions because of the large lateral extent of the displays and their close proximity and relative motion with respect to the Hawaiian islands (Figures 2,3).

Surface weather charts for 24 and 25 March indicate an extensive high pressure area to the northeast of Hawaii with a well developed low to the northwest both at a large range $(>2000 \mathrm{~km})$. An extended cold front, associated with these pressure centres, moved steadily towards the southeast, and came to a halt between 00:00 and 12:00 UT on 25 March at a distance of $\sim 1400 \mathrm{~km}$ from the observing site. Both the orientation and location of the front agree well with the observed wave motion (Figure 2) but its range was relatively large.

In the absence of background winds wave energy from a tropospheric source of apparent period $\sim 5 \mathrm{~min}$ would reach the $\mathrm{OH}$ layer at a quite short ground range of $<100$ $\mathrm{km}$ (assuming the vertical extent of the source region was no greater than the atmospheric scale height) [Hines, 1967]. If the background winds in the intervening atmosphere substantially increased the intrinsic period of the waves on this occasion they could travel very large horizontal distances. This situation would arise if $\overline{\mathbf{u}}-\mathbf{v}_{\mathbf{x}}$ $\left(\sim 50 \mathrm{~ms}^{-1}\right)$ over an extended height interval between the source and the region of observation (equation 1).

On 30 and 31 March surface weather charts show a cold front associated with a developing low and a high pressure region to the north of Hawaii at a range of $-1500 \mathrm{~km}$. Although aligned in a direction similar to that of the $\mathrm{OH}$ wave pattern its location is not consistent with the northward wave motion observed in the nightglow data. To the south of Hawaii there were no obvious weather sources within $30^{\circ}$ of latitude.

\section{In Situ Source}

If the short period waves were generated in the upper atmosphere in the vicinity of the $\mathrm{OH}$ layer then they would most probably have been vertically evanescent. The long lifetimes and the large geographic extent of the wave patterns also suggests that the source regions were extensive and long lasting. One possible mechanism that could account for the observations has been postulated by Tuan et al. [1979]. Under certain conditions long period waves propagating through the upper atmosphere may partially break, generating coherent, small-scale waves of intrinsic period close to the local Brunt-Väisälä period. On both 25 and 31 March $\tau_{\mathrm{b}}$ was found to be about 4.6 min (using spectrometer data of Turnbull and Lowe, [1991]). If both wave patterns were generated with an intrinsic period of this value then the difference in the apparent wave periods may have been the result of differing local wind conditions at the source height on each night. The apparent period on $25 \mathrm{March}$ was very close to $\tau_{b}$ indicating a background wind component $\bar{u} \sim 3 \mathrm{~ms}^{-1}$ in the direction of motion of the wave (equation 1). However, on 31 March a neutral wind $\overline{\mathrm{u}} \sim 38 \mathrm{~ms}^{-1}$ would have been needed to account for an apparent period of $\sim 10 \mathrm{~min}$. Neutral winds of this magnitude and variability are frequently observed at nightglow altitudes but unfortunately there were no coincident measurements over Maui with which to compare these observations.

If the short period waves were generated in situ by this mechanism then their occurrence, speed and direction of motion should be associated with the presence of a large scale wave disturbance on each occasion. Evidence for the presence of long period wave disturbances on both occasions was found in the measurements of the other ALOHA-90 instruments. On 25 March the airborne observations were made to the south of Maui (Figure 2). Sodium lidar measurements were obtained from 08:50 to 15:00 UT (mainly outside the limits of the camera field of 
view). However, close to the equator a strong disturbance of horizontal wavelength $400-550 \mathrm{~km}$ was measured [C.S. Gardner, personal communication, 1991]. Zenith spectrometer measurements from Haleakala show a near linear decrease in $\mathrm{OH}(3,1)$ band intensity during most of the night with a small wave-like disturbance of quasiperiod $\sim 1.2$ hour [Turnbull and Lowe, 1991]. Coincident observations by the Aerospace group using a zenith pointing $C C D$ imager show similar period, low amplitude variations in the $\mathrm{OH}(6,2)$ band emission and the $\mathrm{O}_{2}(0,1)$ Atmospheric band. The disturbance moved towards the southeast at a speed of $50-100 \mathrm{~ms}^{-1}$, in a direction comparable with that of the short period wave pattern [Hecht and Walterscheid, 1991].

On 31 March the $\mathrm{OH}$ emission was brighter and the spectrometer measured large amplitude wave-like disturbance with dominant periods 2.2 and 1.2 hours in both intensity and temperature. The Aerospace images showed that the disturbance was moving at a velocity of $30-50 \mathrm{~ms}^{-1}$ similar in magnitude to that of the short period wave pattern but in a general eastward direction. The aircraft flew almost due west (Figure 3) and measurements over the period 08:00-15:30 UT show peaks in the horizontal spectra with wavelengths of 170 and $340 \mathrm{~km}$ again indicating a large scale wave motion. However, as the aircraft flight path was almost parallel to the $\mathrm{OH}$ wave pattern the true horizontal wavelength may have been much shorter.

\section{Summary}

Observations of extensive $\left(>250,000 \mathrm{~km}^{2}\right)$ linear wave patterns with short apparent periods $(\leq 10 \mathrm{~min})$ and long lifetimes (several hours) are most unusual. Whether these displays are peculiar to low latitude or oceanic sites remains unknown. On 25 March there was a favourably orientated weather front where linearly extensive short period ( $<10 \mathrm{~min}$ ) gravity waves may have been generated. However, if the waves originated in this region then background winds in the intervening atmosphere must have played an important role in considerably increasing their horizontal range. No obvious source was found for the 31 March display.

It appears more likely that the waves reported here were generated in the upper atmosphere in the vicinity of the $\mathrm{OH}$ layer. Both patterns exhibited many of the properties characteristic of the sustained breakdown of a large scale upper atmospheric wave disturbance (possibly of tidal origin). Supporting evidence showing concurrent long period (1-2 hour) mesospheric wave disturbances was found on both occasions. Several other short period $(\leq 10$ min) displays were also imaged during the ALOHA-90 campaign but it is not yet known if they were associated with long period upper atmosphere wave disturbances. Measurements of gravity waves at low latitudes are few and these data may offer new evidence for the in situ generation of short period waves in the upper atmosphere. However, the possibility that the waves were generated by other weather disturbances such as jet streams [see Hines, 1968] or distant thunderstorms [Taylor and Hapgood, 1988] has yet to be investigated.
Acknowledgements. We are most grateful to the director J. Dryden and staff of Holmes and Narver Inc. for arranging the use of the DOE facility on Mt. Haleakala for the measurements. We thank M.J. Hill for his considerable help both prior to and during the campaign and B.S. Lanchester for many useful discussions. We acknowledge our ALOHA-90 colleagues for the use of their data. Funding for this project was provided through the University of Cincinnati as part of the U.S. Air Force Office of Scientific Research MAPSTAR programme.

\section{References}

Armstrong, E.B., Irregularities in the $80-100 \mathrm{~km}$ region: A photographic approach, Radio Sci., 21, 313-318, 1986.

Gardner, C.S., Introduction to ALOHA-90: the airborne lidar and observations of the Hawaiian airglow campaign, Geophys. Res. Lett., this issue, 1991.

Hapgood, M.A., and M.J. Taylor, Analysis of airglow image data, Ann. Geophys., 38, 805-813, 1982.

Hecht, J.H., and R.L. Walterscheid, Observations of the $\mathrm{OH}$ Meinel $(6,2)$ and $\mathrm{O}_{2}$ Atmospheric $(0,1)$ nightglow emissions from Maui during the ALOHA-90 campaign, Geophys. Res. Lett., this issue, 1991.

Hines, C.O., Internal atmospheric gravity waves at ionospheric heights, Can. J. Phys., 38, 1441-1481, 1960.

Hines, C.O., On the nature of travelling ionospheric disturbances launched by low-altitude nuclear explosions, J. Geophys. Res., 72, 1877-1882, 1967.

Hines, C.O., A possible source of waves in noctilucent clouds, J. Atmos. Sci., 25, 937-942, 1968.

Moreels, G., and M. Herse, Photographic evidence of waves around the $85 \mathrm{~km}$ level, Planet. Space Sci., 25 , 265-273, 1977.

Taylor, M.J., M.A. Hapgood, and P. Rothwell, Observations of gravity wave propagation in the OI $(557.7 \mathrm{~nm})$, $\mathrm{Na}(589.2 \mathrm{~nm})$ and the near infrared $\mathrm{OH}$ nightglow emission, Planet. Space Sci., 35, 413-427, 1987.

Taylor, M.J., and M.A. Hapgood, Identification of a thunderstorm as a source of short period gravity waves in the upper atmospheric nightglow emissions, Planet. Space Sci., 36, 975-985, 1988.

Taylor, M.J., and M.J. Hill, Near infrared imaging of hydroxyl wave structure over an ocean site at low latitudes, Geophys. Res. Lett., this issue, 1991.

Tuan, T.F., R. Hedinger, S.M. Silverman, and M. Okuda, On gravity wave induced Brunt-Väisälä oscillations, $\underline{\mathrm{J}}$. Geophys. Res., 84, 393-398, 1979.

Turnbull, D.N., and R.P. Lowe, Temporal variations in the hydroxyl nightglow observed during ALOHA-90, Geophys. Res. Lett., this issue, 1991.

M.J. Taylor and R. Edwards, Physics Department, The University of Southampton, Southampton, SO9 5NH, U.K.

(Received April 5, 1991;

revised June 5, 1991;

accepted June 10, 1991.) 